\title{
MULTI-ENVIRONMENT TRIAL ANALYSIS BY PARAMETRIC AND NON- PARAMETRIC STABILITY PARAMETERS FOR SEED YIELD IN WINTER RAPESEED (Brassica napus L.) GENOTYPES
}

\author{
Yasemin ERDOGDU ${ }^{I^{*}}$, Enver ESENDAL ${ }^{1}$ \\ ${ }^{1}$ Tekirdag Namık Kemal University, Faculty of Agriculture, Department of Field Crops, Tekirdag, \\ TURKEY \\ *Corresponding author: yerdogdu@nku.edu.tr
}

Received: 08.09.2019

\begin{abstract}
The objective of this study was to determine the stability of $\mathbf{1 1}$ different rapeseed genotypes in terms of seed yield, throughout 3 years (2014-2015-2016), 3 locations (Tekirdag, Kurklareli, Edirne), in total 8 environment in Thrace Region. The experiment was designed as a randomized complete block design with four replications. The aim of this study was to determine rapeseed genotypes having a high adaptation for seed yield. Parametric $\left(W_{i}^{2}, b_{i}, S_{d i}^{2}, B_{i}, \sigma_{i}^{2}, r_{i}^{2}, S_{x i}^{2}, C V_{i}\right.$ and $P_{i}$,) and non-parametric $\left(S_{i}^{(2)}, S_{i}^{(3)}, S_{i}^{(6)}\right.$, RS and TOP) stability statistics were used to determine stability of the genotypes. The analysis of variance for seed yield showed that genotypes, environments and genotype by environment interaction all were significant $(P<0,01)$. According to parametric and non-parametric (except TOP methods) stability analysis, genotype Wosry 142 was determined as a well-adapted genotype; genotype Wosry 144 poorly adapted genotype in across environments. Genotype Wosry 142 may be recommended for cultivation in the different environments tested.
\end{abstract}

Keywords: Genotype by environment interactions, stability parameters, winter rapeseed, yield

\section{INTRODUCTION}

Rapeseed (Braccica napus L.) is the second most important oilseed crop cultivated worldwide after soybean with a production of approximately for 2019 is 70.51 million tonnes (FAO, 2021). The widespread use of biodiesel in addition to edible oil has led to an increase in rapeseed production in recent years. In a few decades, rapeseed has become one of the world's most important oilseeds. Rapeseed cultivation also increased rapidly in Turkey and cultivation area, which was 82 hectares in 2000 , increased to 52.510 hectares in 2019 . The total rapeseed production increased from 187 tonnes to 180.000 tonnes during the 2000-2019 periods in Turkey. In the Thrace region of Turkey, which is one of the most important production area of sunflower and rapeseed, rapeseed has to compete with sunflower. However average rapeseed yield of Turkey is $3427 \mathrm{~kg} \mathrm{ha}^{-1}$, the average sunflower yield is $2793 \mathrm{~kg} \mathrm{ha}^{-1}$ (FAO, 2021), and also winter rapeseed is well adapted for production in Thrace region. Thrace region has provided to $39 \%$ of rapeseed production in Turkey (Y1lmaz and Avkıran, 2019). For this reason, it is necessary to determine the appropriate rapeseed genotypes for the Thrace region. However, to date, the number of studies on genotype by environment interaction (GEI) of rapeseed in the Thrace region is quite insufficient.
GEI is an extremely important issue in crop breeding and production (Kang and Gauch, 1996) because genotypes and environments interact to produce an array of phenotypes (Kang, 2002). The phenotypic performance of a genotype may not be the same under diverse agroclimatic conditions (Ali et al., 2002). Although genotypic characteristics and agronomical applications can be controlled, it is not possible to control other environmental factors such as precipitation, temperature and proportional humidity. Therefore, genotypes must be stable against change environmental conditions and successful new varieties must show high performance for seed yield (Becker and Leon, 1988; Akcura et al., 2006).

Seed yield is a very complex quantitative trait, which expression is the result of genotype, environment and the GEI (Nowsad et al., 2016). The occurrence of GEI necessitates multi-environment trials and has resulted in the development and use of numerous measures of stability (Yan and Kang, 2002). Comstock and Moll (1963) obtained data by establishing repeated experiments in various years and locations and investigated the existence of the GEI with variance analyses performed on the obtained data. If genotypes have different values in various environments and this difference is significant, the GEI comes into question for these genotypes. When the 
GEI is determined to be significant, the stabilities of the genotypes are examined.

The numerous stability statistics are available to explain GEI (Yan and Kang, 2002). There are two major approaches (Huehn, 1996). The first and most common approach is parametric which relies on distributional assumptions about genotypic, environmental, and GEI effects. The second major approach is the non-parametric or analytical clustering approach, which relates environments and phenotypes relative to biotic and abiotic environmental factors without making specific modelling assumptions (Sabaghnia, 2006). Non-parametric stability statistics provide a viable alternative to existing parametric measures based on absolute data (Lu, 1995).

When studies conducted on the GEI for seed yield in the rapeseed are examined, it was seen that in the studies conducted by Shafii et al. (1992); Wright et al. (1995); Ali et al. (2002); Ali et al. (2003); Escobar et al. (2011); Marjonovic-Jeromela et al. (2011); Zhang et al. (2011); Moghaddam and Pourdad (2011); Shojaei et al. (2011); George et al. (2012); Tahira and Amjad (2013);
Mashayekh et al. (2014); Mortazavian and Azizi-Nia (2014); Oghan et al. (2016); Sharma and Sardana (2016); Lima et al. (2017), the GEI was determined to be significant and various stability analyses were carried out.

The objectives of this study were to (i) examine the influence of genotype, environment and GEI in terms of seed yield for winter rapeseed; (ii) determine the adaptation and stability performances of promising winter rapeseed genotypes using parametric and non-parametric stability methods; (iii) identify winter rapeseed genotypes that have both high seed yield and stable performance across different environments in Thrace region.

\section{MATERIALS AND METHODS}

Eleven rapeseed genotypes were grown 8 environments in the localities of Edirne, Kirklareli, and Tekirdag during the 2014-2016 growing season at the Thrace region in Turkey. The code, name and origin of these genotypes are listed in Table 1. Location, cropping season, temperature, rainfall, relative humidity, longitude, latitude, and height above sea level for across environment given Table 2.

Table 1. The code, genotype name and origin of the genotypes used in the study

\begin{tabular}{lll}
\hline Code & Genotype name & Origin \\
\hline G1 & Turan & KWS \\
G2 & Rally & Cimsan \\
G3 & Nk Petrol & Syngenta \\
G4 & Nk Caravel & Syngenta \\
G5 & Suzer & Trace Agricultural Research Institute \\
G6 & PR44W29 & P1oneer \\
G7 & Excalibur & Dekalp \\
G8 & Wosry 141 & Euralis \\
G9 & Wosry 142 & Euralis \\
G10 & Wosry 143 & Euralis \\
G11 & Wosry 144 & Euralis \\
\hline
\end{tabular}

Table 2. Code, location, growing season, temperature, rainfall, relative humidity, longitude (E), latitude (N) and height above sea level for across environment

\begin{tabular}{lllllllll}
\hline Code & Location & $\begin{array}{l}\text { Growing } \\
\text { season }\end{array}$ & $\begin{array}{l}\text { Temperature } \\
{ }^{\circ} \mathbf{C}\end{array}$ & $\begin{array}{l}\text { Rain-fall } \\
(\mathbf{m m})\end{array}$ & $\begin{array}{l}\text { Relative } \\
\text { humidity }(\%)\end{array}$ & $\begin{array}{l}\text { Longitude } \\
(\mathbf{E})\end{array}$ & $\begin{array}{l}\text { Latitude } \\
(\mathbf{N})\end{array}$ & $\begin{array}{l}\text { Above sea } \\
\text { level }(\mathbf{m})\end{array}$ \\
\hline E1 & Tekirdag & $2013-2014$ & 13.7 & 478.4 & 79.2 & $40^{\circ} 99^{\prime} 04^{\prime \prime}$ & $27^{\circ} 58^{\prime} 07^{\prime \prime}$ & $10 \mathrm{~m}$ \\
E2 & Tekirdag & $2014-2015$ & 13.3 & 519.9 & 77.6 & $40^{\circ} 99^{\prime} 04^{\prime \prime}$ & $27^{\circ} 58^{\prime} 07^{\prime \prime}$ & $10 \mathrm{~m}$ \\
E3 & Tekirdag & $2015-2016$ & 14.5 & 324.5 & 75.9 & $40^{\circ} 99^{\prime} 04^{\prime \prime}$ & $27^{\circ} 58^{\prime} 07^{\prime \prime}$ & $10 \mathrm{~m}$ \\
E4 & Kirklareli & $2013-2014$ & 12.7 & 647.6 & 73.5 & $41^{\circ} 70^{\prime} 26^{\prime \prime}$ & $27^{\circ} 20^{\prime} 86^{\prime \prime}$ & $232 \mathrm{~m}$ \\
E5 & Kirklareli & $2014-2015$ & 12.4 & 628.2 & 70.2 & $41^{\circ} 70^{\prime} 26^{\prime \prime}$ & $27^{\circ} 20^{\prime} 86^{\prime \prime}$ & $232 \mathrm{~m}$ \\
E6 & Kirklareli & $2015-2016$ & 13.6 & 522.8 & 72.6 & $41^{\circ} 70^{\prime} 26^{\prime \prime}$ & $27^{\circ} 20^{\prime} 86^{\prime \prime}$ & $232 \mathrm{~m}$ \\
E7 & Edirne & $2013-2014$ & 13.3 & 521.6 & 71.3 & $41^{\circ} 64^{\prime} 68^{\prime \prime}$ & $29^{\circ} 59^{\prime} 71^{\prime \prime}$ & $51 \mathrm{~m}$ \\
E8 & Edirne & $2014-2015$ & 13.8 & 530.8 & 71.5 & $4^{\circ} 64^{\prime} 68^{\prime \prime}$ & $29^{\circ} 59^{\prime} 71^{\prime \prime}$ & $51 \mathrm{~m}$ \\
\hline
\end{tabular}

The experimental layout was a randomized complete block design with four replication. Plots were $5 \mathrm{~m}^{2}$ with six rows, each $5 \mathrm{~m}$ long and $20 \mathrm{~cm}$ between rows. The harvested plot size was $3 \mathrm{~m}^{2}$ (there 4 rows at the center of each plot). The seeding density was 175 seed $\mathrm{m}^{2}$. Fertilizer application was $36 \mathrm{~kg} \mathrm{~N} \mathrm{ha}^{-1}$ and $92 \mathrm{~kg} \mathrm{P}_{2} \mathrm{O}_{5} \mathrm{ha}^{-1}$ at planting, $46 \mathrm{~kg} \mathrm{~N} \mathrm{ha}^{-1}$ at the stem elongation stage and
$39 \mathrm{~kg} \mathrm{~N} \mathrm{ha}{ }^{-1}$ beginning of the flowering stage. Crop fungicide and insecticide were applied to plants recommended rates.

\section{Statistical Analysis}

A combined ANOVA was firs performed for the mean seed yield values of 11 rapeseed genotypes in across 8 
environments 2013-2014, 2014-2015, 2015-2016 in Tekirdag, Kırklareli and 2013-2014, 2015-2016 in Edirne ecological conditions. Statistical analyses were carried out using JMP-7. The F-protected least significant difference (LSD) was calculated at the 0.05 probability level according to Steel and Torrie (1986). Then 9 parametric stability parameters were studied in accordance Wrick's (1962) $W_{i}^{2}=$ ecovalance; Finlay and Wilkinson's (1963) $b_{i}=$ regression coefficient; Eberhart and Russel's (1966) $b_{i}=$ regression coefficient and $S_{d i}^{2}=$ deviations from regression; Perkins and Jinks's (1968) and Baker's (1969) $B_{i}=$ regression coefficient and $S_{d i}^{2}=$ deviations from regression; Shukla's (1972) $\sigma_{i}^{2}=$ stability variance; Pinthus's (1973) $r_{i}^{2}=$ coefficient of determination; Francis and Kannenberg's (1978) $S_{x i}^{2}=$ environmental variance; $C V_{i}=$ coefficient of variation; Lin and Binns's (1986) $P_{i}=$ superiority index. Secondly 5 non-parametric stability parameters were studied in accordance with Nassar and Huehn's (1987) $S_{i}^{(3)}=$ sum of the absolute deviations of the squares of ranks for each genotype; $S_{i}^{(6)}=$ the sum of squares of ranks for each genotype relative to the mean of ranks; Huehn's (1990) $S_{i}^{(2)}=$ genotype between ranks variance over n environments; Kang's (1988) RS= rank sum and Fox et al.'s (1990) TOP= number of sites at which the genotype occurred in the top third of the ranks. In addition, two-way relations between all stability parameters were determined by correlation analysis. All stability statistical analyses were performed using the SAS (Statistical Analyses Systems) program (SAS Institute, 1999).

\section{RESULTS AND DISCUSSION}

A combined analysis of variance for seed yield showed that genotype, environment, and GEI were significant at $\mathrm{P}<0.01$ (Table 3). The average seed yield values of the genotype, environment, and GEI of 11 rapeseed genotypes obtained from 8 environments are shown in Table 4.
When the environments were examined, it was seen that seed yield differed between 1189.3-1937.2 $\mathrm{kg} \mathrm{ha}^{-}$ ${ }^{1}$,that the highest seed yield was obtained in the E7 environment and that the lowest seed yield was obtained in the E2 environment; In the study, the total temperature values of the surroundings during the rapeseed growing season and the average temperature values during the flowering season differed. During the whole growing season, the total temperature values of the environments varied by $2.1{ }^{\circ} \mathrm{C}$ degrees. In addition, when the total precipitation regimes are examined, there is a significant difference between the environments. Seed yield differences between environments may be caused by factors such as temperature and precipitation, because rapeseed is sensitive to water stress and high temperature stress during post-anthesis period and strong genotype and environment interactions (Shafii et al., 1992; Gunasekera et al., 2006; Cullis et al., 2010; Zhang et al., 2013).

when the genotypes were examined, the seed yield differed between $1382.5-1605.0 \mathrm{~kg} \mathrm{ha}^{-1}$, that the highest seed yield was obtained from the G10 genotype and that the lowest seed yield was obtained from the G6 genotype. These results indicated that rapeseed genotypes had significant differences for seed yield over different environments. In similar studies, it has been revealed that there is a significant difference in seed yield between the environments in rapeseed (Gunasekera, 2006; ElNakhlawy, 2009; Marjanovic-Jeromela et al., 2011; Nowosad et al., 2016).

When the GEI was examined, the seed yield ranged between $1057.5-2127.5 \mathrm{~kg} \mathrm{ha}^{-1}$ and that the highest seed yield was obtained from the G11 genotype in the E7 environment, and that the lowest seed yield was obtained again from the G11 genotype in the E2 environment (Table 4). Seed yield in rapeseed vary with genotype, environment and GEI (Shafii et al., 1992; Si et al., 2003; $\mathrm{Si}$ and Walton, 2004; Gunasekera et al., 2006; Moghaddam and Pourdad, 2011; Zhang et al., 2013; Nowosad et al., 2016). The fact that the GEI was determined to be significant shows that the stability conditions of genotypes are different in terms of seed yield.

Table 3. Analysis of variance for winter rapeseed seed yield in 8 envirnment

\begin{tabular}{lllll}
\hline Source of variation & d.f & Sum of square & Mean square & F \\
\hline Environment $(\mathrm{E})$ & 7 & 15151397 & 2164485.28 & $193.49^{* *}$ \\
Error 1 (R/E) & 24 & 403611 & 16817.12 & $1.50^{\text {ns }}$ \\
Genotype $(\mathrm{G})$ & 10 & 1538152 & 153815.20 & $13.75^{* *}$ \\
$\mathrm{G} \times \mathrm{E}$ & 70 & 8793593 & 125621.9 & $11.22^{* *}$ \\
Error 2 & 240 & 2684764 & & \\
Total & 351 & 28571518 & & \\
\hline $\mathrm{CV}(\%)=1.40$ & & &
\end{tabular}


Table 4. Mean seed yield of winter rapeseed genotypes tested across 8 environments $\left(\mathrm{kg} \mathrm{ha}^{-1}\right)$

\begin{tabular}{|c|c|c|c|c|c|c|c|c|c|}
\hline Genotype & E1 & E2 & E3 & E4 & E5 & E6 & E7 & E8 & Mean* \\
\hline G1 & 1410.0 & 1322.5 & 1397.5 & 1362.5 & 1432.5 & 1305.0 & 2022.5 & 1180.0 & $1429.0 \mathrm{de}$ \\
\hline $\mathrm{G} 2$ & 1407.5 & 1107.5 & 1617.5 & 1485.0 & 1412.5 & 1455.0 & 1605.0 & 1482.5 & $1446.5 \mathrm{~cd}$ \\
\hline G3 & 1977.5 & 1227.5 & 1187.5 & 1597.5 & 1582.5 & 1530.0 & 1615.0 & 1457.5 & $1521.8 \mathrm{~b}$ \\
\hline G4 & 1635.0 & 1105.0 & 1287.5 & 1777.5 & 1587.5 & 1197.5 & 1915.0 & 1277.5 & $1472.8 \mathrm{bcd}$ \\
\hline G5 & 1195.0 & 1347.5 & 1627.5 & 1715.0 & 1257.5 & 1442.5 & 2065.0 & 1272.5 & $1490.3 \mathrm{bc}$ \\
\hline G6 & 1175.0 & 1275.0 & 1482.5 & 1225.0 & 1257.5 & 1320.0 & 2020.0 & 1305.0 & $1382.5 \mathrm{e}$ \\
\hline G7 & 1397.5 & 1117.5 & 1602.5 & 1517.5 & 1560.0 & 1225.0 & 1927.5 & 1252.5 & $1450.0 \mathrm{~cd}$ \\
\hline G8 & 1130.0 & 1130.0 & 1437.5 & 1537.5 & 1277.5 & 1585.0 & 2035.0 & 1305.0 & $1429.6 \mathrm{de}$ \\
\hline G9 & 1392.5 & 1155.0 & 1600.0 & 1727.5 & 1485.0 & 1470.0 & 1947.5 & 1385.0 & $1520.3 \mathrm{bc}$ \\
\hline G10 & 1380.0 & 1237.5 & 2015.0 & 1690.0 & 1712.5 & 1485.0 & 2030.0 & 1290.0 & $1605.0 \mathrm{a}$ \\
\hline G11 & 1470.0 & 1057.5 & 1330.0 & 1975.0 & 1925.0 & 1602.5 & 2127.5 & 1250.0 & $1592.1 \mathrm{a}$ \\
\hline Mean* & $1415.4 \mathrm{~d}$ & $1189.3 \mathrm{f}$ & $1507.7 \mathrm{c}$ & $1600.9 \mathrm{~b}$ & $1499.0 \mathrm{c}$ & $1419.7 \mathrm{~d}$ & $1937.2 \mathrm{a}$ & $1314.3 \mathrm{e}$ & \\
\hline
\end{tabular}

$*$ LSD\% $:$ Genotype $=40.7 \quad$ Environment $=44.4 \quad$ Genotype $\times$ Environment=147.3

\section{Parametric methods}

The results of 9 parametric stability parameters and mean seed yields for 11 rapeseed genotypes at the 8 environments are presented in Table 5. According to Wricke (1962), if the $W_{i}^{2}$ of a genotype is low, the stability of that genotype is high. The highest $W_{i}^{2}$ was calculated in the G3 genotype, followed by the genotypes G11 and G10. The lowest $W_{i}^{2}$ was calculated in the G9 genotype, followed by the genotypes G7, G1 and G2. With the stability analysis, it was found that the most stable genotypes with $W_{i}^{2}$ values near 0 were G9, G7 and G1 respectively (Table 5).

Genotypes G10 and G11 had higher seed yields and $b_{i}$ values above 1.0 these genotypes are sensitive to environmental variations and would be suggested for cultivation under favorable environments (Table 5). Genotypes G9 and G5 had higher seed yields and $b_{i}$ values near 1.0 these genotypes are stable to environmental variations and would be suggested for cultivation across environments. Genotypes G4 and G6 had lowest avarage yield and and $b_{i}$ values near 1.0 these genotypes are stable. Genotypes G7 and G8 had lowest avarage yield and $b_{i}$ values above 1.0 these genotypes poorly adapted across environments. Genotype G3 with $b_{i}<1$ and higher average yields was adapted across unfavorable environments. Genotype G2 with $b_{i}<1$ and lowest average yield was adapted across unfavorable environments. Genotype G1 had lowest avarage yield and and $b_{i}$ values near 1.0 these genotype poorly adapted across environments (Finlay and Wilkinson, 1963)

Eberhart and Russel (1966) reported that in order to determine the adaptation and stability conditions of genotypes, the $S_{d i}^{2}$ should be used in addition to the $b_{i}$, that the $b_{i}$ value of a stable genotype should be near 1 , that the genotype average should be higher than the overall average and that the $S_{d i}^{2}$ value should be near 0 .
As a result of the study $b_{i}$, it was found that the genotypes that were near 1 were G1, G6, G9 and G7; that the genotypes with averages higher than the overall average were G10, G11, G3 and G9; and that the genotypes with the $S_{d i}^{2}$ values near 0 were G9, G7, G2 and G1 (Table 5). In accordance with these results, the G9 genotype was determined to be the most suitable genotype for the environments where the experiment was conducted.

Perkins and Jinks (1968) and Baker (1969), used the $B_{i}$ value as stability criteria. When the $B_{i}$ values of seed yield obtained in the study were examined, it was found that the genotypes that were the nearest to 0 were G1, G6 and G9 respectively. Considering the fact that the $S_{d i}^{2}$ should be low, it was found that the lowest genotypes were G9, G7 ve G2 and respectively (Table 5). In accordance with these results, the G9 genotype was determined to be the most suitable genotype for the environments where the experiment was conducted.

Shukla (1972) developed an unbiased estimate using $\sigma_{i}^{2}$ of genotypes. The highest $\sigma_{i}^{2}$ that was obtained in the study was acquired from G3, G11 and G10 and the lowest $\sigma_{i}^{2}$ was obtained from the genotypes G9, G7 and G1 (Table 5). In accordance with these values, the genotypes G9, G7 and G1, which are the nearest to 0 , were found to be the most stable genotypes. Also, there is a linear relationship between the $\sigma_{i}^{2}$ and the $W_{i}^{2}$. The stability conditions of the genotypes were found to be the same according to both stability analysis.

Pinthus (1973) used the $r_{i}^{2}$ as a stability parameter and reported that the genotypes with $r_{i}^{2}$ near 1 were stable. As a result of the analysis the genotypes that were the nearest to the $r_{i}^{2} 1$ were G9, G7, G1 and G10 respectively. The genotypes with $r_{i}^{2}$ near 0 which had the lowest stabilities were G3, G2, G4 and G5 (Table 5). In accordance with these results, the G9 genotype was determined to be the most suitable genotype for the environments where the experiment was conducted. 
Francis and Kennenberg (1978) used the $S_{x i}^{2}$ of each genotype and the $C V_{i}$ as the stability criterion. According to this stability analysis, the $S_{x i}^{2}$ and $C V_{i}$ values of a stable genotype should be near 0 and its genotype average should be higher than the overall average. The genotypes that were the nearest to the $S_{x i}^{2} 0$ were G2, G9 and G3; and the genotypes that were the furthest from 0 were $\mathrm{G} 11$, G10 and G8. When the $C V_{i}$ of the genotypes were considered, the genotypes that were the nearest to the $C V_{i}$ 0 were G2, G9 and G3; and the genotypes that were the furthest to 0 were G11, G8 and G4 (Table 5). In accordance with these results, the G2 and G9 genotypes were determined to be the most suitable genotypes for the environments where the experiment was conducted.

Lin and Binns (1986) used the concept of $P_{i}$ to determine the stabilities of genotypes. And if the $P_{i}$ value of a genotype is near 0 , the stability of that genotype is high. The genotypes that were the nearest to the $P_{i} 0$ were G10, G11 and G9 respectively; and the genotypes that were the furthest from it were G6, G8 and G1 (Table 5). In accordance with these results, the G10, G11 and G9 genotypes were determined to be the most suitable genotype.

\section{Non-parametric methods}

The results of 5 non-parametric stability parameters and mean seed yields for 11 rapeseed genotypes at the 8 environments are presented in Table 6. According to Huehn (1979) and Nassar and Huehn (1987) the $S_{i}^{(2)}, S_{i}^{(3)}$ and $S_{i}^{(6)}$ reported that these obtained values needed to be near " 0 " for a genotype to be stable; and that zero variance showed high determination. In the light of these findings, the most stable genotypes according to the $S_{i}^{(2)}$ analysis result were G9, G7 and G10 respectively; the most stable genotypes, according to the $S_{i}^{(3)}$ analysis result were again G9, G7 and G10 respectively and the most stable genotypes according to the $S_{i}^{(6)}$ analysis result were G7, G9 and G6 respectively. The genotypes with the lowest stabilities were G11, G3 and $\mathrm{G} 4$ respectively according to the $S_{i}^{(2)}$ analysis result, G11, G3 and G5 according to the $S_{i}^{(3)}$ analysis result, and G11, G5 and G3 according to the $S_{i}^{(6)}$ analysis result (Table 6). In accordance with these results, the G9 and G7genotypes were determined to be the most suitable genotype.

Table 6. Mean seed yield values $\left(\mathrm{kg} \mathrm{ha}^{-1}\right)$ and non-parametric stability parameters of 11 winter rapeseed genotypes across 8 environment

\begin{tabular}{|c|c|c|c|c|c|c|}
\hline \multirow[b]{2}{*}{ Genotypes } & \multicolumn{6}{|c|}{ Non-parametric Methods } \\
\hline & $\bar{X}$ & $S_{i}^{(2)}$ & $S_{i}^{(3)}$ & $S_{i}^{(6)}$ & $\mathbf{R S}$ & TOP \\
\hline G1 & 1429.0 & 11.55 & 9.71 & 2.85 & 13 & 12.5 \\
\hline $\mathrm{G} 2$ & 1446.5 & 11.12 & 12.30 & 3.38 & 13 & 25.0 \\
\hline G3 & 1521.8 & 14.26 & 17.42 & 4.28 & 14 & 37.5 \\
\hline G4 & 1472.8 & 14.12 & 15.33 & 3.92 & 13 & 37.5 \\
\hline G5 & 1490.3 & 10.28 & 17.05 & 4.68 & 11 & 37.5 \\
\hline G6 & 1382.5 & 12.78 & 8.32 & 2.71 & 19 & 12.5 \\
\hline G7 & 1450.0 & 5.71 & 4.06 & 1.86 & 9 & 0.0 \\
\hline G8 & 1429.6 & 12.55 & 10.05 & 2.99 & 13 & 25.0 \\
\hline G9 & 1520.3 & 2.28 & 3.33 & 1.90 & 5 & 25.0 \\
\hline G10 & 1605.0 & 9.71 & 7.88 & 2.94 & 10 & 25.0 \\
\hline G11 & 1592.1 & 18.98 & 31.10 & 6.97 & 12 & 62.5 \\
\hline
\end{tabular}

KEY: $\bar{X}=$ seed yield $\left(\mathrm{kg} \mathrm{ha}^{-1}\right) ; S_{i}^{(2)}=$ genotype between ranks variance over $\mathrm{n}$ environments (Huehn, 1990); $S_{i}^{(3)}=$ sum of the absolute deviations of the squares of ranks for each genotype (Nassar and Huehn, 1987); $S_{i}^{(6)}=$ the sum of squares of ranks for each genotype relative to the mean of ranks (Nassar and Huehn, 1987); RS= rank sum (Kang, 1988); TOP= number of sites at which the genotype occurred in the top third of the ranks (Fox et al., 1990)

According to Kang (1988) if the RS of a genotype is low, the stability of that genotype is high. The genotypes with low RS values were G9, G7 and G10 respectively, while the genotypes with high RS values were G6 and G3 (Table 5).In accordance with these values, the genotypes G9 and G7 were found to be the most stable genotypes.

To reveal the stabilities of genotypes, Fox et al. (1990) suggested the TOP stability analysis, which is a nonparametric stability analysis obtained with the rate of inclusion in the top three ranks in each environment according to the performance rankings (from the highest) of the genotypes that were tried in various environments. The genotypes with TOP values near 100 are the genotypes with the highest stabilities. While the genotypes with the highest TOP values were G11; the genotypes with the lowest TOP values were G7 genotype (Table 6). In accordance with these values, the genotype G11was found to be the most stable genotypes. 


\section{Relationship between parametric and non-parametric methods conclusions}

The rank correlations between seed yield and stability methods are given in Table 7. Seed yield is significantly correlated with TOP $(\mathrm{P}<0.05)$ and showed a negative and significant correlation with $P_{i}(\mathrm{P}<0.01) . \quad W_{i}^{2}$ is significantly correlated with $S_{d i}^{2}, \sigma_{i}^{2}(\mathrm{P}<0.01)$ and with the methods of $S_{i}^{(2)}, S_{i}^{(3)}, S_{i}^{(6)}$, TOP $(\mathrm{P}<0.05)$. and showed a negative and significant correlation with $r_{i}^{2}$ $(\mathrm{P}<0.01)$. The $b_{i}$ is significantly correlated with $B_{i}, r_{i}^{2}$, $S_{x i}^{2}, \quad C V_{i}, \quad(\mathrm{P}<0.01) . \quad S_{d i}^{2}$ is $\quad$ significantly correlated with $\sigma_{i}^{2}, S_{i}^{(2)}(\mathrm{P}<0.01)$ and with the methods of $S_{i}^{(3)}$, $S_{i}^{(6)},(\mathrm{P}<0.05)$ and showed a negative and significant correlation with $r_{i}^{2}(\mathrm{P}<0.01)$. The $B_{i}$ is significantly correlated with $r_{i}^{2}, S_{x i}^{2}, C V_{i}(\mathrm{P}<0.01) . \sigma_{i}^{2}$ is significantly correlated with $S_{i}^{(2)}, S_{i}^{(3)}, \quad S_{i}^{(6)}$,TOP, $\quad(\mathrm{P}<0.05)$, and showed a negative and significant correlation with $r_{i}^{2}$ $(\mathrm{P}<0.01) . S_{x i}^{2}$ is significantly correlated with $C V_{i}(\mathrm{P}<0.01)$ and with the methods of $S_{i}^{(3)}, S_{i}^{(6)}$, TOP, $(\mathrm{P}<0.05) . P_{i}$ is significantly correlated with $\mathrm{RS}, \quad(\mathrm{P}<0.05) . \quad S_{i}^{(2)}$ is significantly correlated with $S_{i}^{(3)}, S_{i}^{(6)}, \quad(\mathrm{P}<0.01)$ and with the methods of RS and TOP $(\mathrm{P}<0.05) . S_{i}^{(3)}$ is significantly correlated with, $S_{i}^{(6)}$ and TOP $(\mathrm{P}<0.01)$. $S_{i}^{(6)}$ is significantly correlated with TOP $(\mathrm{P}<0.01)$.

Table 7. Spearman's (1910) rank correlation coefficients between the different parametric and nonparametric stability parameters for seed yield of 11 winter rapeseed genotypes

\begin{tabular}{|c|c|c|c|c|c|c|c|c|c|c|c|c|c|c|}
\hline & $\bar{X}$ & $W_{i}^{2}$ & $b_{i}$ & $S_{d i}^{2}$ & $B_{i}$ & $\sigma_{i}^{2}$ & $r_{i}^{2}$ & $S_{x i}^{2}$ & $C V_{i}$ & $P_{i}$ & $S_{i}^{(2)}$ & $S_{i}^{(3)}$ & $S_{i}^{(6)}$ & $\mathrm{RS}$ \\
\hline$W_{i}^{2}$ & 0.38 & & & & & & & & & & & & & \\
\hline$b_{i}$ & 0.24 & -0.38 & & & & & & & & & & & & \\
\hline$S_{d i}^{2}$ & 0.38 & $0.96^{* *}$ & -0.22 & & & & & & & & & & & \\
\hline$B_{i}$ & 0.24 & -0.38 & $1.00 * *$ & -0.22 & & & & & & & & & & \\
\hline$\sigma_{i}^{2}$ & 0.38 & $1.00 * *$ & -0.38 & $0.96^{* *}$ & -0.38 & & & & & & & & & \\
\hline$r_{i}^{2}$ & -0.09 & $-0.86^{* *}$ & $0.76^{* * *}$ & -0.76 *** & $0.76^{* *}$ & $-0.86^{* * *}$ & & & & & & & & \\
\hline$S_{x i}^{2}$ & 0.52 & 0.28 & $0.77 * *$ & 0.42 & $0.77 * *$ & 0.28 & 0.19 & & & & & & & \\
\hline$C V_{i}$ & 0.25 & 0.16 & $0.78 * *$ & 0.36 & $0.78 * *$ & 0.16 & 0.25 & $0.93 * *$ & & & & & & \\
\hline$P_{i}$ & $-0.88^{* * *}$ & -0.07 & -0.21 & -0.04 & -0.21 & -0.07 & -0.08 & -0.27 & -0.02 & & & & & \\
\hline$S_{i}^{(2)}$ & 0.11 & $0.70^{*}$ & 0.05 & $0.74 * *$ & 0.05 & $0.70 *$ & -0.45 & 0.54 & 0.48 & 0.18 & & & & \\
\hline$S_{i}^{(3)}$ & 0.42 & $0.67 *$ & 0.16 & $0.66^{*}$ & 0.16 & $0.67 *$ & -0.40 & $0.63 *$ & 0.46 & -0.14 & $0.83 * *$ & & & \\
\hline$S_{i}^{(6)}$ & 0.48 & $0.65^{*}$ & 0.21 & $0.65^{*}$ & 0.21 & $0.65^{*}$ & -0.36 & $0.67 *$ & 0.49 & -0.19 & $0.80 * *$ & $0.99 * *$ & & \\
\hline RS & -0.49 & 0.42 & -0.25 & 0.48 & -0.25 & 0.42 & -0.40 & 0.02 & 0.15 & $0.72 *$ & $0.68^{*}$ & 0.26 & 0.22 & \\
\hline TOP & $0.62^{*}$ & $0.60^{*}$ & 0.19 & 0.60 & 0.19 & $0.60 *$ & -0.35 & $0.61^{*}$ & 0.41 & -0.36 & $0.63^{*}$ & $0.89^{* * *}$ & $0.90 * *$ & 0.00 \\
\hline
\end{tabular}

\section{CONCLUSION}

This study has provided the evaluation of the GEI in terms of seed yield of different winter rapeseed genotypes under the ecological conditions of the Thrace region. For this, stability of genotypes was examined using different 9 parametric and 5 non-parametric stability analysis methods. Genotip, environment and GEI played a significant role in terms of seed yield in this study. When considering the mean seed yields of the genotypes over the environments, it was determined that genotypes G10, G11, G3, G9 and G5 had the highest seed yield whereas the lowest seed yield was obtained from G6, G1 and G8 genotypes. According to parametric stability measures $\left(W_{i}^{2}, b_{i}, S_{d i}^{2}, B_{i}, \sigma_{i}^{2}, r_{i}^{2}, S_{x i}^{2}, C V_{i}\right.$, and $\left.P_{i}\right)$ G9, G6 and G1 genotypes were determined to be stable genotypes.
According to non-parametric stability measures $\left(S_{i}^{(2)}, S_{i}^{(3)}, S_{i}^{(6)}, \mathrm{RS}\right.$ and TOP) G9, G6 and G11 genotypes were determined to be stable genotypes. Genotype G9 was demonstrated superior adaptability with high yield performance in many environments. G9 genotype would be suggested for cultivation under changing environmental conditions.

\section{ACKNOWLEDGMENTS}

This study is part of Corresponding Author Ph.D. thesis titled as "Determination of Genotype $\times$ Environment Interactions in Terms of Important Agronomic Traits of Some Rapeseed (Brassica napus L.) Genotype Under the Ecological Conditions of Thrace Region". This research was supported by the 
NKUBAP.00.24.AR.14.23 project. The authors wish to thank all of them for their support.

\section{LITERATURE CITED}

Akcura, M., Y. Kaya, S. Taner and R. Ayranci. 2006. Parametric stability analyses for grain yield of durum wheat. Plant Soil and Environment. 52: 254-261.

Ali, N., F. Javıdfar and A.A. Attary. 2002. Stability analysis of seed yield in winter type rapeseed (Brassica napus) varieties. Pak. J. Bot. 34: 151-155.

Ali, N., F. Javidfar and M.Y. Mirza. 2003. Selection of stable rapeseed (Brassica napus L.) genotypes through regression analysis. Pak. J. Bot. 35: 175-180.

Baker, R.J. 1969. Genotype-environment interactions in yield of wheat. Canadian Journal of Plant Sci. 49: 743-751.

Becker, H.C. and J. Leon. 1988. Stability analysis in plant breeding. Plant Breeding. 101: 1-23.

Comstock, R.E. and R.H. Moll. 1963. Genotyp $\times$ environment interactions. Statistical Genetics and Plant Breeding. No. REP-1173. CIMMYT

Cullis, B.R., A.B. Smith, C.P. Beeck and W.A. Cowling. 2010. Analysis of yield and oil from a series of canola breeding trials. Part II. Exploring variety by environment interaction using factor analysis. Genome. 53(11): 1002-1016.

Eberhart, S.A. and W.A. Russell. 1966. Stability parameters for comparing varieties. Crops Sci. 6: 36-40.

El-Nakhlawy, F.S. 2009. Performance of canola (Brassica napas L.) seed yield, yield components and seed quality under the effects of four genotypes and nitrogen fertilizer rates. Meteorology, Environment and Arid Land Agriculture Sciences. 20(2).

Escobar, M., M. Berti, I. Matus, M. Tapia and B. Johnson. 2011. Genotype $\times$ environment interaction in canola (Brassica napus L.) seed yield in Chile. Chilean Journal of Agricultural Research. 71: 175-186.

FAOSTAT. 2021. Data stat year 2021 Food Agriculture Organization, (http://www.fao.org/faostat/en/) verified 2 April 2021. Rome, Italy.

Finlay, K.W. and G.N. Wilkinson. 1963. The analysis of adaptation in a plant breeding programme. Aust. Journal of Agricultural Research. 14: 742-754.

Fox, P.N., B. Skovmand, B.K. Thompson, H.J. Braun and R. Cormier. 1990. Yield and adaptation of hexaploid spring triticale. Euphytica. 47: 57-64.

Francis, T.R. and W. Kannenberg. 1978. Yield stability studies in short-season 1.a. descriptive method for grouping genotypes. Can. J. Plant Sci. 58: 1029-1034.

George, N., K. Tungate, C. Beeck and M. Stamm. 2012. Exploring genotype by environment interaction in winter canola in North Carolina. Journal of Agricultural Sci. 2: 237244.

Gunasekera, C.P., L.D. Martin, K.H.M. Siddique, and G.H. Walton, G.H. 2006. Genotype by environment interactions of Indian mustard (Brassica juncea L.) and canola (B. napus L.) in Mediterranean-type environments: 1. Crop growth and seed yield. European Journal of Agronomy. 25(1), 1-12.

Huehn, M. 1979. Beitrage zur erfassung der phanotypischen stabilitat. EDV Med Biol.10:112-117.

Huehn, M. 1990. Nonparametric measures of phenotypic stability. Part 1: Theory. Euphytica. 47(3): 189-194.

Huehn, M. 1996. Non-parametric analysis of genotype $\mathrm{x}$ environment interactions by ranks. Genotype by environment interaction. CRC Press, Boca Raton, FL, 213228.

Kang, M.S. 1988. A rank-sum method for selecting highyielding, stable corn genotypes. Cereal Research Communication. 16: 113-115.
Kang, M.S. and H.G. Gauch. 1996. Genotype-by-Environment Interaction. CRC press, Boca Raton, FL.

Lima, L.H.D.S., A.L. Braccini, C.A. Scapim, G.G. Piccinin and R.M. Ponce. 2017. Adaptability and stability of canola hybrids in different sowing dates. Revista Ciência Agronomica. 48: 374-380.

Lin, C.S., M.R. Binns and L.P. Lefkovitch. 1986. Stability analysis: where do we stand? Crop Sci. 26: 894-900.

Lu, H.Y. 1995. PC-SAS program for estimating Hühn's nonparametric stability statistics. Agronomy journal. 87(5): 888-891.

Marjanovic-Jeromela, A., N. Nag, J. Gvozdanovic-Varga, N. Hristov, A. Kondic-Spica, M.V.R. Marinkovic. 2011. Genotype environment interaction for seed yield per plant in rapeseed using AMMI model. Pesq. Agropec. Bras. Brasilia. 46: 174-181.

Mashayekh, A., A. Mohamadi and S. Gharanjick. 2014. Evaluation of canola genotypes for yield stability in the four regions in Iran. Bulletin of Environment, Pharmacology and Life Sci. 3: 123-128.

Moghaddam, M.J. and S.S. Pourdad. 2011. Genotype × environment interactions and simultaneous selection for high oil yield and stability in rainfed warm areas rapeseed (Brassica napus L.) from Iran. Euphytica. 180: 321-335.

Mortazavian, S.M.M. and S. Az11-nıa. 2014. Nonparametric stability analysis in multi-environment trial of canola. Turkish Journal of Field Crops. 19: 108-117.

Nassar, R. and M. Huehn. 1987. Studies on estimation of phenotypic stability: Tests of significance for nonparametric measures of phenotypic stability. Biometrics. 45-53.

Nowosad, K., A. Liersch, W. Pop ${ }^{3}$ awska and J. Bocianowski. 2016. Genotype by environment interaction for seed yield in rapeseed (Brassica napus L.) using additive main effects and multiplicative interaction model. Euphytica. 208(1): 187194.

Oghan, H.A., N. Sabaghnia, V. Rameeh, H.R. Fanaee and E. Hezarjeribi. 2016. Univariate stability analysis of genotype $\times$ environment interaction of oilseed rape seed yield. Acta Universitatis Agriculturae et Silviculturae Mendelianae Brunensis. 64: 1625-1634.

Perkins, J.M. and J.L. Jinks. 1968. Environmental and genotypeenvironmental components of variability III. multiple lines and crosses. Heredity. 23: 339-356.

Pinthus, M.J. 1973. Estimate of genotypic value: a proposed method. Euphytica 22: 121-123.

Sabaghnia, N., H. Dehghani, and S.H. Sabaghpour. 2006. Nonparametric methods for interpreting genotype $\times$ environment interaction of lentil genotypes. Crop Sci. 46(3): 1100-1106.

SAS Institute. 1999. SAS/STAT User's Guide. 2nd edition. SAS Institute Inc. Cary. NC

Shafii, B., K.A. Mahler, W.J. Price and D.L. Auld. 1992. Genotype $\times$ environment interaction effects on winter rapeseed yield and oil content. Crop Sci. 32: 922-927.

Sharma, P. and V. Sardana. 2016. Evaluating morphophysiological and quality traits to compliment seed yield under changing climatic conditions in Brassicas. Journal of Environmental Biology. 37: 493-502.

Shojaei, S.H., K. Mostafavi, M. Khodarahmi and M. Zabet. 2011. Response study of canola (Brassica napus L.) cultivars to multi-environments using genotype plus genotype environment interaction (GGE) biplot method in Iran. African Journal of Biotechnology. 10: 10877-10881.

Shukla, G.K. 1972. Some statistical aspects of partitioning genotype-environmental components of variability. Heredity. 29: 237-245. 
Si, P. and G.H. Walton. 2004. Determinants of oil concentration and seed yield in canola and Indian mustard in the lower rainfall areas of Western Australia. Aust. J. Agric. Res. 55: 367-377.

Si, P., R.J. Mailer, N. Galwey and D.W. Turner. 2003. Influence of genotype and environment on oil and protein concentrations of canola (Brassica napus L.) grown across southern Australia. Aust. J. Agric. Res. 54: 397-407.

Spearman, C. 1910. Correlation calculated from faulty data. British Journal of Psychology. 3: 271-295.

Steel, R.G.D. and J.H. Torrie. 1986. Principles and procedures of statistics: a biometrical approach. McGraw-Hill.

Tahira, R.A., M.A. Khan and M. Amjad. 2013. Stability analysis of canola (Brassica napus L.) genotypes in Pakistan. Global Advanced Research Journal of Agricultural Sci. 2: 270-275.

Wood, J.T. 1976. The use of environmental variablesin the interpretation of genotype-environment interaction. Heredity. 37: 1-7.

Wricke, G. 1962. Uber eine methode zur erfassung der ökologischen streubreite in feldversuchen $\mathrm{Z}$. Pflanzenzüchtung. 47: 92-96.
Wright, P.R., J.M. Morgan, R.S. Jessop and A. Cass. 1995. Comparative adaptation of canola (Brassica juncea) to soil water deficits: yield and yield components. Field Crops Research. 42: 1-13.

Yan, W. and M.S. Kang 2002. GGE biplot analysis: A graphical tool for breeders, geneticists, and agronomists. CRC press.

Yilmaz, H. and B. Avkıran 2020. Analysis of Canola (Rapeseed) Production Cost and Income in Context of Oilseeds Production Support Policies: A Case Study from Trakya Region of Turkey. Åêîîì̀êèà îišîîğèâăgaäåå. 67(2).

Zhang, H., J.D. Berger and S.P. Milroy. 2011. Genotypex environment interaction of canola (Brassica napus L.) in multi-environment trials. Proceedings of the 17th Australian Research Assembly on Brassicas. 50-6.

Zhang, H., J.D. Berger and S.P. Milroy. 2013. Genotypex environment interaction studies highlight the role of phenology in specific adaptation of canola (Brassica napus) to contrasting Mediterranean climates. Field Crops Research. 144: 77-88. 